Journal of the Magnetics Society of Japan Vol. 15 Supplement, No. S2 (1991)

(c) 1991 by The Magnetics Society of Japan

\title{
MAGNETIC AND RECORDING CHARACTERISTICS OF COCr FILMS WITH NiFe AND Ti UNDERLAYERS
}

\author{
Zheng YANG, Ming-Long YAN and Pei ZHENG
}

\begin{abstract}
Research Institute of Magnetic Materials, Lanzhou University, Lanzhou 730000, Gansu, China
\end{abstract}

\begin{abstract}
The influence of the Ti underlayer on the structure and magnetic properties of $\mathrm{CoCr}$ and $\mathrm{CoCr} / \mathrm{NiFe}$ films has been studied. The recording characteristics of double layer $\mathrm{CoCr} / \mathrm{NiFe}$ perpendicular magnetic recording media with $\mathrm{Ti}$ film under the $\mathrm{NiFe}$ film or inserted between $\mathrm{CoCr}$ film and NiFe film was measured and discussed. Although the coercivity and effective magnetic anisotropy field of media increase with increasing the thickness of $\mathrm{CoCr}$ film $t_{c o c r}$, but the output voltage and $\mathrm{D}_{50}$ of media became smaller.
\end{abstract}

\section{INTRODUCTION}

It was shown that magnetic properties of $\mathrm{CoCr}$ thin films depend strongly on its crystallographic structure[1], and several underlayers have been proposed in order to improve the magnetic and recording characteristics of $\mathrm{CoCr}$ films[2]. This paper reported a dependence of magnetic properties and $\triangle \theta_{50}$ of the $\mathrm{CoCr}$ film on the substrate temperature and its thickness. The areal homogeneity of a coercivity for $\mathrm{RF}$ magnetron sputtered $\mathrm{CoCr}$ film was determined. an influence of the $\mathrm{Ti}$ underlayer on the structure and magnetic properties of single $\mathrm{CoCr}$ film and an effect of the $\mathrm{Ti}$ underlayer on recording performance of double layer $\mathrm{CoCr} / \mathrm{NiFe}$ media with Ti film under the NiFe film or inserted between $\mathrm{CoCr}$ film and $\mathrm{NiFe}$ film were measured and discussed. It was found that the output voltage and $\mathrm{D}_{50}$ strongly depend on the thickness of $\mathrm{CoCr}$ film.

\section{EXPERIMENTAL}

$\mathrm{CoCr}, \mathrm{NiFe}$ and $\mathrm{Ti}$ films were prepared by RF magnetron sputtering, using a sputtering system of model SPF-312. The compositions of the 6 inch targets use were Co $80 \%$ $\mathrm{Cr} 20 \%$ and $\mathrm{Ni} 79.7 \% \mathrm{Fe} 16.3 \% \mathrm{Mo} 3 \%$. respectively. The substrates were glass slides and $50 \mu \mathrm{m}$ thick polyimide films which was degassed at $250^{\circ} \mathrm{C}$ before deposition. Table 1 gives the sputtering conditions for magnetic layers and $\mathrm{Ti}$ layer.

The crystallographic structure was investigated by $\mathrm{X}$ - ray diffraction. The degree of $c$-axis orientation of the hep CoCr films was evaluated from the halfvalue width $\triangle \theta_{50}$ of the (00.2) plane rocking curve. The film thickness was determind by multiple beam interferometry.

The saturation magnetization $\mathrm{M}_{\mathbf{S}}$, coercivity $\mathrm{H}_{\mathrm{C}}$ and magnetic anisotropy field $\mathrm{H}_{\mathrm{K}}$ were measured using a highly sensitive vibrating sample magnetometer model VSM $5 S-15$ with a maximum applied field of 16 KOe. The magnetic properties measured with the magnetic field applied in the sample plane are denoted by the suffix $\|$, and those measured with magnetic field applied normal to the plane by the suffix $\perp$. The perpendicular 
magnetic anisotropy field $\mathrm{H}_{\mathrm{K} \perp}$ was determined from an in-plane hysteresis loop.

Table 1 Sputtering conditions for $\mathrm{COCr}$, NiFe and Ti films

\begin{tabular}{|c|c|c|}
\hline $\begin{array}{l}\text { Background pressure } \\
\text { Target-Substrate distance } \\
\text { Substrate rotation }\end{array}$ & & $\begin{array}{l}\leqslant 1 \times 10^{-3} \text { tort } \\
60 \mathrm{~mm} \\
10 \mathrm{RPM}\end{array}$ \\
\hline Sputterering pressure & $\begin{array}{r}\mathrm{CoCr} \\
\mathrm{NiFe} \\
\mathrm{Ti}\end{array}$ & $\begin{array}{l}1 \times 10^{-3} \text { torr } \\
6 \times 10^{-3} \text { torr } \\
1 \times 10^{-3} \text { tort }\end{array}$ \\
\hline Power density & $\begin{array}{r}\mathrm{CoCr} \\
\mathrm{NiFe} \\
\mathrm{Ti}\end{array}$ & $\begin{array}{l}5.5 \mathrm{~W} / \mathrm{cm}^{2} \\
\text { 8. } 5 \mathrm{~W} / \mathrm{cm}^{2} \\
\text { 4. } 4 \mathrm{~W} / \mathrm{cm}^{2}\end{array}$ \\
\hline Temperature of substrates & $\begin{array}{r}\mathrm{CoO} \\
\mathrm{NiFe} \\
\mathrm{Ti}\end{array}$ & $\begin{array}{c}180^{\circ} \mathrm{C} \sim 200^{\circ} \mathrm{C} \\
20^{\circ} \mathrm{C} \\
100^{\circ} \mathrm{C}\end{array}$ \\
\hline Deposition rate & $\begin{array}{r}\mathrm{CoCt} \\
\mathrm{NiFe} \\
\mathrm{Ti}\end{array}$ & $\begin{array}{l}130 \dot{\mathrm{A}} / \mathrm{min} \\
200 \dot{\mathrm{A}} / \mathrm{min} \\
44 \dot{\mathrm{A}} / \mathrm{min}\end{array}$ \\
\hline
\end{tabular}

The read-write characteristics of a 3.5 inch diameter flexible disk were measured by using a flexible disk test unit. The parameters of the SPT head [4] are as follows: thickness and saturation flux density of the main pole: $\mathrm{T}_{\mathrm{m}}=0.3 \mu \mathrm{m}, \mathrm{B}_{\mathrm{s}}=12.5 \mathrm{KG}$; track width $\mathrm{W}$ $=100 \mu \mathrm{m}$; Number of turns $\mathrm{N}=50$ and inductance $\mathrm{L}=4.0 \mu \mathrm{H}$.

\section{RESULTS AND DISCUSSIONS}

\section{Magnetic Properties of the CoCr Films}

The magnetic properties of $\mathrm{CoCr}$ films depend on the sputtering condition. The temperature of substrate $\mathrm{T}_{\text {sub }}$ and film thickness $t_{c o r}$ have great influence on film ${ }^{\prime} s$ characteristics. The Table 2 gives the influence of $T_{\text {sub }}$ on properties of $\mathrm{CoCr}$ films. We can see that the $\mathrm{M}_{\mathrm{S}}$ and $\mathrm{H}_{\mathrm{C} \perp}$ increase with an increase of $\mathrm{T}_{\text {sub }}$.
Table 2 The dependence of proporties of Coct films on $T_{\text {sub }}$

\begin{tabular}{|c|c|c|c|c|c|c|}
\hline \multirow{2}{*}{$\begin{array}{l}\mathrm{T}_{\text {sub }} \\
\text { (C) }\end{array}$} & \multirow{2}{*}{$\underset{(\mathrm{deg} .)}{\triangle \theta_{50}}$} & \multicolumn{2}{|c|}{$M_{*}(\mathrm{G})$} & \multicolumn{2}{|c|}{$\mathrm{H}_{c}(\mathrm{Oe})$} & \multirow{2}{*}{$\begin{array}{l}\operatorname{tac} r \\
(\mathrm{~A})\end{array}$} \\
\hline & & 1 & $\|$ & 1 & $\|$ & \\
\hline 20 & 10 & 440 & 400 & 250 & 175 & 1320 \\
\hline 100 & 12 & 410 & 410 & 250 & 250 & 1430 \\
\hline 150 & 13 & 430 & 430 & 400 & 195 & 1450 \\
\hline 200 & 13 & 450 & 450 & 500 & 180 & 1460 \\
\hline 250 & - & 580 & 580 & 500 & 184 & 1040 \\
\hline
\end{tabular}

In the Table 3 was summarized the thickness dependence of characteristics of $\mathrm{CoCr}$ films. With an increase of $t_{c o c r}$ the $\mathrm{H}_{\mathrm{C} \perp}, \mathrm{M}_{\mathrm{r} \perp} / \mathrm{M}_{\mathrm{s}}$ and $\mathrm{H}_{\mathrm{K} \perp}$ of films increase, while its $H_{r \|} / M_{s}$ and $\triangle \theta_{50}$ decrease.

Table 3 The dependence of properties of CoCr films on teac

\begin{tabular}{|c|c|c|c|c|c|c|}
\hline \multirow{2}{*}{$\begin{array}{l}t_{c o c} \\
(\dot{A})\end{array}$} & \multicolumn{2}{|c|}{$\mathrm{H}_{\mathrm{c}}(\mathrm{Oe})$} & \multicolumn{2}{|c|}{$\mathrm{Mr} / \mathrm{Ms}(0 / 0)$} & \multirow{2}{*}{$\begin{array}{l}\mathrm{H}_{\mathrm{K} \perp} \\
(\mathrm{Oe})\end{array}$} & \multirow{2}{*}{$\frac{\Delta \theta_{50}}{(\operatorname{deg} .)}$} \\
\hline & $\perp$ & $\|$ & $\perp$ & $\|$ & & \\
\hline 520 & 400 & 210 & 7.5 & 59 & 600 & 16.8 \\
\hline 2000 & 520 & 200 & 13 & 30 & 1400 & 9.2 \\
\hline 3100 & 740 & 220 & 15 & 24 & 2800 & 8.0 \\
\hline 5900 & 740 & 220 & 14 & 17 & 3800 & 7.0 \\
\hline
\end{tabular}

The areal homogeneity of the deposited medium is an important issue. The magnetic properties need to be fairly constant in the area for testing. In the Table 4 was summarized the distribution of the $\mathrm{H}_{\mathrm{C}}$ and $\mathrm{H}_{\mathrm{K} \perp}$ of

Table 4 The distribution of $\mathrm{H}_{c}$ and $\mathrm{H}_{\mathrm{K}}$ for sputtercd $\mathrm{COCr}$ film

\begin{tabular}{c|c|c|c}
\hline \multirow{2}{*}{$\begin{array}{c}\text { Distance from the } \\
\text { center of medium } \mathrm{R}(\mathrm{mm})\end{array}$} & \multicolumn{2}{|c|}{$\mathrm{H}_{\mathrm{C}}(\mathrm{Oe})$} & \multirow{2}{*}{$\mathrm{H}_{\mathbf{L} \perp}$ (KOe) } \\
\cline { 2 - 3 } & 1 & $\|$ & \\
\hline 0 & 700 & 300 & 4.8 \\
10 & 700 & 300 & 3.6 \\
20 & 710 & 250 & 3.9 \\
30 & 700 & 210 & 3.8 \\
40 & 650 & 200 & 2.9 \\
50 & 600 & 200 & 2.4 \\
70 & 400 & 200 & 2.0 \\
90 & 320 & 200 & 1.7 \\
\hline
\end{tabular}


$\mathrm{CoCr}$ film along the radius direction. So, it is possible to cut out a 3.5 inch diameter flexible disk sample from the central area of deposited medium.

\section{Read-Write Characteristics of Media}

The magnetic properties and $\triangle \theta_{50}$ of $\mathrm{CoCr}$ film with and without $\mathrm{Ti}$ underlayers are given in the Table 5 . The coercivity $\mathrm{H}_{\mathrm{C} \perp}$ and effective magnetic anisotropy field $\mathrm{H}_{\mathrm{K} \perp}$

Table 5 Characteristies of $\mathrm{CoCr}$ films

\begin{tabular}{c|c|c|c|c|c}
\hline \multirow{2}{*}{ sample } & \multirow{2}{*}{$\begin{array}{c}\Delta \theta_{50} \\
\text { (deg.) }\end{array}$} & \multicolumn{2}{|c|}{$\mathrm{H}_{\mathrm{c}}(\mathrm{Oe})$} & \multirow{2}{*}{$\begin{array}{c}\mathrm{H}_{\mathbf{K} \perp} \\
(\mathrm{Oe})\end{array}$} & $\begin{array}{c}\mathrm{M}_{\mathbf{s}} \\
\text { (G) }\end{array}$ \\
\cline { 3 - 5 } $\mathrm{A}$ & 12 & 500 & 210 & 1800 & 475 \\
$\mathrm{~B}$ & 10 & 560 & 250 & 2400 & 465 \\
\hline
\end{tabular}

$\mathrm{A}=\mathrm{CoCr}(1960 \dot{\mathrm{A}}) / \mathrm{Sub}$.

$\mathrm{B}=\mathrm{CoCr}(1960 \mathrm{~A}) / \operatorname{Ti}(300 \mathrm{~A}) / \mathrm{Sub}$.

are all increased by the existence of a Ti underlayer. The $\triangle \theta_{50}$ of the sample $B$ is smaller than that of the sample $A$. No diffraction peaks were observed other than the one for the hep $\mathrm{CoCr}(00.2)$ plane in the sample B. To clarify the cause which leads to the improvement of characteristics for $\mathrm{CoCr}$ film with $\mathrm{Ti}$ underlayer, the film thickness dependence of the structure of Ti films were examined. The $\mathrm{X}$ - ray diffraction patterns (Fig. 1) show that the structure of $\mathrm{Ti}$ films with

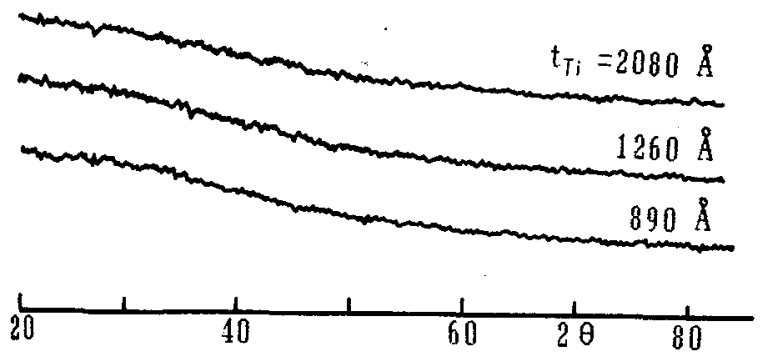

Fig. 1 X-ray diffraction patterns of $\mathrm{Ti}$ films with different thickness $t_{T i}$ different thickness was amorphous. Our experiments indicate that the $\mathrm{CoCr} / \mathrm{NiFe}$ double layer media with $\mathrm{Ti}$ underlayers have improved high recording characteristics as shown in Table 6. It was found that the $\mathrm{CoCr} / \mathrm{NiFe}$ double layer medium with inserted $\mathrm{Ti}$ layer have more smooth surface and better envelope cuves of flexible disk sample (Fig. 3), but the inserted Ti layer between the $\mathrm{CoCr}$ film and NiFe film decreases the re-

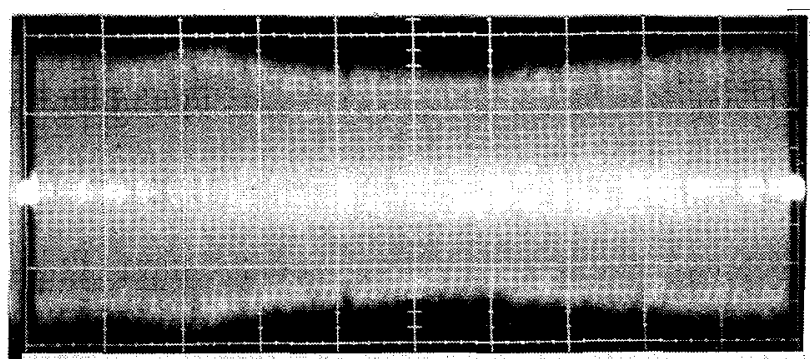

Fig. 3 Reproduced Signal enve lope at 20KRRPI (Full horizontal Scan Corresponds to one revolution of the disk $1,0.1$ div)

Table 6 Read-write characteristics of 3.5 inch diameter flexible disks

\begin{tabular}{|c|c|c|c|}
\hline $\begin{array}{l}\text { Number of } \\
\text { Samples }\end{array}$ & $\begin{array}{c}\text { Structure of media } \\
\text { thickness of layers }(\mu \mathrm{m})\end{array}$ & $\begin{array}{l}\mathrm{E}_{\mathrm{p}}(\mathrm{mv}) \\
(25 \mathrm{KBPI})\end{array}$ & $\begin{array}{l}\mathrm{D}_{50}(\mathrm{KBPI}) \\
\left(\mathrm{T}_{\mathrm{m}}=0.3 \mu \mathrm{m}\right)\end{array}$ \\
\hline 1 & $\begin{array}{c}\mathrm{C} \alpha \mathrm{Cr} / \mathrm{NiFe} / \mathrm{Ti} / \mathrm{sub} \\
0.10 / 0.50 / 0.04\end{array}$ & 255 & 88 \\
\hline 2 & $\begin{array}{c}\mathrm{CoCr} / \mathrm{NiFe} / \mathrm{Ti} / \mathrm{sub} \\
0.15 / 0.50 / 0.04\end{array}$ & 200 & 64 \\
\hline 3 & $\begin{array}{c}\mathrm{CoCr} / \mathrm{NiFe} / \mathrm{Ti} / \mathrm{sub} \\
0.20 / 0.50 / 0.04\end{array}$ & 240 & 54 \\
\hline 4 & $\begin{array}{c}\mathrm{CoCr} / \mathrm{Ti} / \mathrm{NiFe} / \mathrm{sub} \\
0.10 / 0.01 / 0.50\end{array}$ & 175 & 54 \\
\hline 5 & $\begin{array}{c}\mathrm{CoCr} / \mathrm{Ti} / \mathrm{NiFe} / \mathrm{sub} \\
0.15 / 0.01 / 0.50\end{array}$ & 200 & 32 \\
\hline 6 & $\begin{array}{c}\mathrm{CoCr} / \mathrm{NiFe} / \mathrm{sub} \\
0.20 / 0.50\end{array}$ & 220 & 45 \\
\hline
\end{tabular}




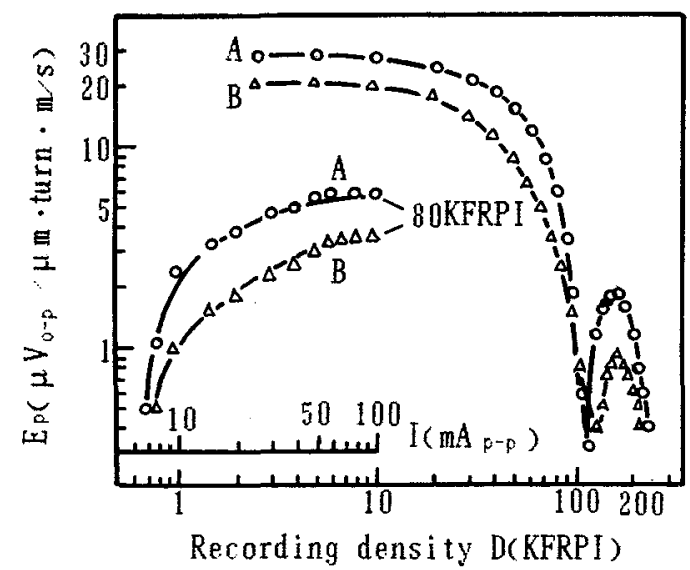

Fig. 2 Recording and reproduced characteristics of media $\mathrm{A}$ ( CoCr NiFe $\mathrm{Ti}$ sub) and $\mathrm{B}$ ( CoCr Ti, NiFe sub)

produced volatage at low density and $D_{50}$ (Fig. 2) . It is necessary to further investigation to clarify the effect of inserted Ti underlayer [3]. Fig. 4 shows the density response curves for $\mathrm{CoCr} / \mathrm{NiFe}$ double layer media with different thickness of $\mathrm{CoCr}$ films $t_{\mathrm{coc}}$. Although with an increase of $t_{c a c}$ the magnetic properties and the degree of $\mathrm{c}$-axis orientation of $\mathrm{CoCr}$ films were improved [Table $3]$, but the output voltage and $D_{50}$ became smaller.

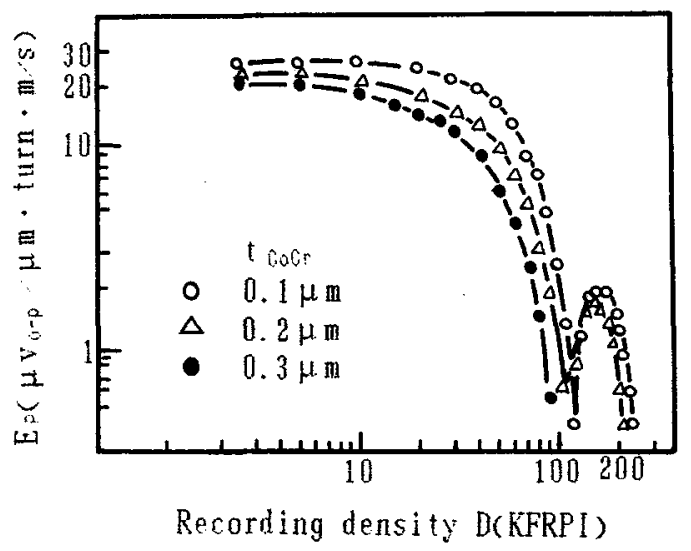

Fig. 4 Density response curves for $\mathrm{Co}-\mathrm{Cr}$ films of different thickness

\section{CONCLUSIONS}

As a final conclusion, we may state that the structure of sputtered Ti films was of amorphous. The $\mathrm{Ti}$ underlayer improve the magnetic and recording characteristics of the single $\mathrm{CoCr}$ film and $\mathrm{CoCr} / \mathrm{NiFe}$ double layer media. The $\mathrm{CoCr} / \mathrm{NiFe}$ media with inserted Ti layer have more smooth surface and better envelope curve of 3.5 inch diamter flexible samples, but their reproduced voltage and $D_{50}$ were decreased. Although with increasing the $t_{\text {cocr }}$ the $\mathrm{H}_{\mathrm{C} \perp}$ and $\mathrm{H}_{\mathrm{K} \perp}$ of double layer media increase, but their output voltage and $D_{50}$ became smaller. It means that in this case the medium thickness loss is dominant factor.

\section{ACKNOWLEDGEMENT}

The authors wish to thank prof. S. Iwasaki of Tohoku Institute of Technology, Prof. Y. Nakamura and Dr. K. Ouchi of Tohoku University for their valuable advice and encouragement. They also thank Mr. Yong - Long Zhao for his help in measurements.

\section{REFERENCES}

[1] O. Kitakami, Y. Ogawa and H. Fujiwara, IEEE Trans. Magn., Vol. MAG -24 , PP. 2353-2355, 1988.

[2] M. Futamoto, Y. Honda, H. Kakibayashi and K. Yoshida, IEEE Trans. Magn., Vol. MAG-21, PP. 1426-1428, 1985.

[3] S. Tadokoro, K. Ouchi, Y. Nakamura and S. Iwasaki, J. Magn. Soc. of Japan, Vol. 13, PP. 149-152, 1989.

[4] S. Yamamoto, Y. Nakamura and S. Iwasaki, IEEE Trans. Magn., Vol. MAG -23, PP. 2070-2072, 1987. 